\title{
Principles and Practice of a Neuropsychological Approach to Conducting Independent Educational Evaluations
}

\author{
Richard S. Ziegler ${ }^{1}$
}

Received: 19 June 2015 /Revised: 11 March 2016/Accepted: 14 March 2016/Published online: 28 March 2016

(C) American Academy of Pediatric Neuropsychology 2016

\begin{abstract}
Pediatric clinical neuropsychological evaluations often compliment traditional psychoeducational evaluations and can facilitate the special education evaluation process in determining eligibility and providing recommendations to enhance a child's progress. Many pediatric neuropsychologists have medical-legal experience along with knowledge of advanced assessment techniques. As a profession, pediatric neuropsychologists are in increasing demand to conduct independent educational evaluations. This article highlights the laws governing the Independent Educational Evaluation (IEE) and the basic procedures for providing IEEs.
\end{abstract}

Keywords Independent educational evaluation · Special education $\cdot$ Forensic $\cdot$ Assessment

\section{Introduction}

This article reflects the experience of this author conducting independent educational evaluations from a neuropsychological perspective over the past 20 years. The Independent Educational Evaluation (IEE) comes under the heading of a procedural safeguard for parents to obtain an outside evaluation when they disagree with the public school districts' evaluation as part of the Individuals with Disabilities Education Improvement Act (IDEA 2004, 34 CFR 2006). The IEE can also be utilized as a dispute resolution tool, when both parents and a school district agree on the need for an independent view of the child's functioning and their educational program.

Richard S. Ziegler

zieg1002@umn.edu

1 University of Minnesota Twin Cities, Minneapolis, MN, USA
Pediatric neuropsychologists are uniquely positioned to provide IEEs by virtue of their training, understanding of brain-behavior relationships, and the inescapable fact that their clinical evaluations often contain data and information derived from a child's educational setting. Virtually all pediatric neuropsychological evaluations contain recommendations to facilitate a child's progress in their educational setting. Many typical neuropsychological reports contain recommendations for special education eligibility, common related service therapies, and specific therapies that may fall under special education eligibility categories. For example, if a child meets special education criteria for specific learning disability, and phonological awareness was an area of weakness or impairment, a neuropsychological report may recommend a phonics-based individualized reading program. The infusion of neuropsychological concepts into the school setting and especially the training of school psychologists has evolved for over a decade (Hale and Fiorello 2004). Hurewitz and Kerr (2011) provide an excellent overview of the neuropsychologist's role in special education. These include "determining referral questions, obtaining outside information, choosing assessments, considering the legal constructs of questions, reviewing discrepant results from other evaluations and Individual Education Plans and communicating ideas" (p. 1058).

IEEs can be conducted from many professional perspectives including psychologists, physicians (e.g., psychiatrists), behavior analysts, physical therapists, occupational therapists, speech and language pathologists, and specialists in the area of deaf and hard of hearing and vision. A combination of the areas of specialty can also be combined in a single IEE to form a multilayered IEE approach with the ultimate goal in determining special education eligibility and whether a child needs a specific mode or combination of modes of special education intervention based on objective evaluation findings. 
While there may be a general impression among evaluators, special educators, and administrators that there is a rise in the number of requests for IEEs, there is no objective published data to indicate this is a fact. The US Department of Education has no published data on how many IEEs are requested on an annual basis. It should be noted, however, that a perusal of education law practice websites do sometimes mention an increasing utilization of the IEE as a procedural safeguard and in dispute resolution.

\section{Understanding the Law: Statutes, Regulations, and Rules}

A basic understanding of special education law is essential when conducting IEEs. The Individuals with Disabilities Education Improvement Act (IDEA 2004) is the federal law that underlies the provision of special education in public education in the USA (20 U.S.C. $\S \S 1400$, et seq., 34 CFR 300). Public school districts are mandated to find all children with disabilities that reside in their geographic boundaries. This requirement is known as the "child find mandate" (20 USC $\S 1412 \mathrm{~A}(3))$.

The IDEA includes rules of procedure for resolving disputes between parents and schools. These rules include mediation, due process hearings, and appeals to state or federal court. In a due process hearing, a trained hearing officer serves as a judge and considers evidence from records, direct testimony, and legal briefs. Following a due process hearing, the hearing officer renders a legally binding decision. Since the due process hearing is a legal proceeding, a party will often choose to be represented by an attorney.

The starting point for special educational eligibility is an evaluation conducted by the child's school district child study team that covers all areas of suspected disability. These evaluations are conducted by a multidisciplinary team that can include regular education teachers, special education teachers, school psychologists, and other related service specialized professionals. The results are written in a formal evaluation report. Following the evaluation, team members convene in a formal meeting that includes the parents and sometimes the student. It is during this meeting that the evaluation results are considered to determine if the child meets or does not meet specific special education criteria. If a child is found to meet special education eligibility, the team uses the evaluation findings to determine the child's Present Levels of Educational Performance (PLEP). The PLEP is then used to develop an Individual Education Plan (IEP) that defines that child's special education program. The IEP must be reasonably calculated to bring about meaningful benefit from their special educational program (Burlington Sch. Committee v. Dept. of Educ. 1985; Board of Education v. Rowley 1982).
As noted above, IEEs are a procedural safeguard under the IDEA, which is the federal law. Each statute requires a federal agency to write regulations in accordance with the law. In the case of the IDEA, it is the responsibility of the Department of Education, Office of Special Education Programs (OSEP), and Office of Special Education and Rehabilitation Services (OSERS) to write the federal regulations. Each state must promulgate special education rules in accordance with the federal law and corresponding regulations that guide the IEP team with specific rules for special education eligibility.

The law governing IEEs is vague. Table 1 is the exact wording of the law. The term "public" agency means a public school district.

The interpretation of this law by school districts has been controversial. For example, under (e) Agency criteria, the qualification of the examiner may be interpreted as indicating that only school psychologists can conduct an IEE or that an IEE may only be conducted in a school because of the specific reference to location. It should be noted, however, that the actual assessment of a student does not need to be conducted within the student's school, nor can only school psychologists conduct the psychometric assessments.

Many of the controversies over who can conduct an IEE are highlighted in a letter to Dr. Stephanie Petska, Director of Special Education for the State of Wisconsin from Patricia J. Guard who was the Acting Director of the Office of Special Education Programs in 2001. The letter advises that criteria prohibiting IEE examiners who are associated with private schools, organizations advocating the interests of parents, and organizations that advocate particular instructional approaches in the area of educating children with disabilities and IEE examiners with a history of consistently acting as an expert witness against public schools are unrelated to an examiner's ability to conduct an evaluation and undermine the parents ability to obtain an independent evaluation. Further, a district cannot restrict an examiner who does not have recent and extensive experience in the public schools.

The Supreme Court has clarified the role of the IEE in the case of Schaffer v. Weast (2005), which placed the burden of proof in due process hearing on the parents (plaintiff). As part of this decision, Justice O'Conner wrote, "They (parents) also have the right to an "independent educational evaluation of the [ir] child." Ibid. The regulations clarify this entitlement by providing that a "parent has the right to an independent educational evaluation at public expense if the parent disagrees with an evaluation obtained by the public agency." (34 CFR § 300.502(b)(1) (2005). The IDEA thus ensures parents' access to an expert who can evaluate all the materials that the school must make available and who can give an independent opinion. They are not left to challenge the government without a realistic opportunity to access the necessary evidence or without an expert with the firepower to match the opposition. 
Table $1 \S 300.502$ Independent Educational Evaluation

(a) General. (1) The parents of a child with a disability have the right under this part to obtain an independent educational evaluation of the child, subject to paragraphs (b) through (e) of this section.

(2) Each public agency must provide to parents, upon request for an independent educational evaluation, information about where an independent educational evaluation may be obtained, and the agency criteria applicable for independent educational evaluations as set forth in paragraph (e) of this section.

(3) For the purposes of this subpart-

(i) Independent educational evaluation means an evaluation conducted by a qualified examiner who is not employed by the public agency responsible for the education of the child in question; and

(ii) Public expense means that the public agency either pays for the full cost of the evaluation or ensures that the evaluation is otherwise provided at no cost to the parent, consistent with $\S 300.103$.

(b) Parent right to evaluation at public expense.

(1) A parent has the right to an independent educational evaluation at public expense if the parent disagrees with an evaluation obtained by the public agency, subject to the conditions in paragraphs (b) (2) through (4) of this section.

(2) If a parent requests an independent educational evaluation at public expense, the public agency must, without unnecessary delay, either-

(i) File a due process complaint to request a hearing to show that its evaluation is appropriate; or

(ii) Ensure that an independent educational evaluation is provided at public expense, unless the agency demonstrates in a hearing pursuant to $\S \S 300.507$ through 300.513 that the evaluation obtained by the parent did not meet agency criteria.

(3) If the public agency files a due process complaint notice to request a hearing and the final decision is that the agency's evaluation is appropriate, the parent still has the right to an independent educational evaluation, but not at public expense.

(4) If a parent requests an independent educational evaluation, the public agency may ask for the parent's reason why he or she objects to the public evaluation. However, the public agency may not require the parent to provide an explanation and may not unreasonably delay either providing the independent educational evaluation at public expense or filing a due process complaint to request a due process hearing to defend the public evaluation.

(5) A parent is entitled to only one independent educational evaluation at public expense each time the public agency conducts an evaluation with which the parent disagrees.

(c) Parent-initiated evaluations. If the parent obtains an independent educational evaluation at public expense or shares with the public agency an evaluation obtained at private expense, the results of the evaluation-

(1) Must be considered by the public agency, if it meets agency criteria, in any decision made with respect to the provision of FAPE to the child; and

(2) May be presented by any party as evidence at a hearing on a due process complaint under subpart $\mathrm{E}$ of this part regarding that child.

(d) Requests for evaluations by hearing officers. If a hearing officer requests an independent educational evaluation as part of a hearing on a due process complaint, the cost of the evaluation must be at public expense.

(e) Agency criteria. (1) If an independent educational evaluation is at public expense, the criteria under which the evaluation is obtained, including the location of the evaluation and the qualifications of the examiner must be the same as the criteria that the public agency uses when it initiates an evaluation, to the extent those criteria are consistent with the parent's right to an independent educational evaluation.

(2) Except for the criteria described in paragraph (e) (1) of this section, a public agency may not impose conditions or timelines related to obtaining an independent educational evaluation at public expense.

\section{Special Hierarchy and Culture}

In undertaking an IEE, it is important to consider the special education hierarchy. This ranges from front-line providers including special education teachers, related service specialists including speech, physical, and occupational therapists, school psychologists, paraprofessionals, and social workers. Administratively, there are often case managers, coordinators per disability area, assistant directors, and directors.

Special education programs are rule and procedure bound. There are specific timelines for providing evaluations and specialized services. There is strict adherence to criteria for eligibility for special education classification. Decisions regarding eligibility and specific service delivery are based on team consensus, not the recommendation of an outside provider or specific diagnostic impressions.

\section{Psychoeducational Evaluations Versus Neuropsychological Evaluations}

By their very nature, school-based evaluations tend to be more focused on school-based issues. They may fail to consider problems and issues that occur outside the school that may be affecting academic, behavioral, and social skill development. While outside medical and mental health records should be considered as part of a special education evaluation, they are often not. For example, psychoactive medications can have significant implications on how a child processes information and regulate their behavior. However, medication effects are sometimes not considered fully, if at all, by evaluation teams.

The knowledge base of neuropsychology bridges and integrates multiple disciplines. Therefore, a neuropsychological 
evaluation often compliments and combines the goals of a typical psychoeducational evaluation. Pediatric neuropsychologists are in a unique position to provide advanced assessment and treatment recommendations to children with disabling conditions based on their knowledge of brain-behavior relationships, psychopharmacology, rehabilitation, and developmental trajectories and a general understanding of the evidence base for treatments including those that may be deployed in a special education setting. The neuropsychological evaluation is more interested in what underlies a child's disabling condition than its mere identification. The notion that underlying processing deficits inform treatment and programming directions is central to understanding a child's neuropsychological status and the general goal of a neuropsychological evaluation.

A neuropsychologist by benefit of practicing in the community are often experts in accessing and referring to other behavioral and medical specialists including pediatric neurology, child and adolescent psychiatry, developmental/ behavioral pediatrics, clinical psychology/psychotherapy, behavior analysis, and treatment facilities - day treatment and residential.

\section{Conducting an IEE}

\section{IEE Goals}

At the basic level, the primary goals of an IEE are to assist the educational team in the determination of special educational eligibility and to recommend appropriate special educational interventions. Associated goals include identifying the effects of functional deficits on academic performance and behavioral and social/emotional functioning (especially self-regulation within the educational setting) and analyzing and critiquing special educational programming to determine educational progress (benefit) and educational harm. It is also important to identify needs that may have been overlooked in previous evaluations or education plans or a failure to evaluate areas of disability that should have been suspected. If appropriate, the IEE should make specific recommendations about the delivery of specialized instruction including the frequency, intensity, and methodology of instruction. Referral recommendations for outside evaluations and treatments and to determine ways other agencies can respond to the need of the student (IDEA and state requirements for interagency collaborations) are very important.

When a due process hearing is eminent, the IEE findings and opinions tend to support one side over the other. The findings of the IEE may lead the parties to settlement. If the parties cannot come to an agreement, the IEE is used to inform and educate the hearing officer both by written report and direct testimony at hearing.

\section{Referral Sources}

IEEs are most frequently requested by parents when they disagree with the school district's evaluation. As such, the request for an IEE is usually associated with a conflict. Some conflicts result in the parent's obtaining advocacy in the form of legal council or a specialized education advocate. However, there are times when school districts will also request an IEE when they are unable to assess the needs of a student or when an evaluation process requires a level of expertise that a district is unable to provide. There are a minority of cases when an IEE is requested by an independent hearing officer in the run-up to a due process hearing. As noted in the law, parents also have a right to pay for their own IEE if the district refuses to make one available at public expense. If a parent requests an IEE at public expense, the public agency must, without unnecessary delay, either file a due process complaint to request a hearing to show that its evaluation is appropriate or ensure that an independent educational evaluation is provided at public expense. While this may seem straightforward, it is a rare occurrence to have a school district file for a due process hearing to defend their evaluation. Generally, if the district refuses to provide an IEE, most parents will not press the issue. First, the prospect of going to a due process hearing is ill advised without legal counsel and inordinately expensive. It is usually more expensive than the cost of a parent-initiated IEE. Second, it may be necessary to hire an outside expert to review the school district's evaluation and associated educational records in order to obtain an opinion about the appropriateness of the school district's evaluation (Table 2).

When a parent requests an IEE, the school district often has a list of providers. However, parents have a right to choose an evaluator not on a district's list, and an IEE can proceed and be considered by the team as long as the evaluation is consistent with agency criteria.

\section{The IEE as a Forensic Evaluation}

Even when a school district agrees to provide an IEE at public expense, there is the potential that parties may disagree on aspects or findings of an evaluation or the components of an IEP. This can result in the need for the parties to resolve the dispute through a due process hearing. Therefore, given the potential of attorney involvement, the possibility of testifying

Table 2 IEE referral sources

Attorney for the plaintiff

Attorney for the district

District without attorney

Parent without attorney

Hearing officers - administrative law judges 
at a hearing, and the prospects of assigning cause or blame, it is best to treat any IEE as a forensic evaluation (Committee on Ethical Guidelines for Forensic Psychologists 1991; Packer and Borum 2003).

Knowing your role in conducting an IEE is essential. As noted above, the law only requires that the evaluator cannot be an employee of the district and the evaluation meets district criteria. However, the overarching goal is of independence and objectivity. The examiner must have the capacity and willingness to be informed by multiple perspectives (parent, student, educator) and advocate only the objective evaluation findings.

\section{First Contacts}

Depending on the referral source(s), first contacts can range from parents and school district administrators to attorneys representing the school district or parents. Regardless of who makes the first contact, it is important to arrange a contact with a school administrator. This person should serve as a liaison to coordinate the scheduling of observations and the dissemination of behavioral rating scales. Depending on that nature of the dispute, the school administrator may also be responsible for compiling and sending out the child's educational record for review. In the first contact with a parent, it is important to emphasize that the evaluation is independent, highlighting the limits of confidentiality and the prospect of opinions that are not necessarily supportive of their point of view. This is especially important when a referral for an IEE comes from an attorney representing the student. In this context, parents may be predisposed to believing that independent evaluator may see things their way.

\section{Formal Proposal for Evaluation}

In most cases in which a district agrees to an IEE at public expense, a formal proposal is often requested. In order to provide a reasonable proposal, a brief review of the child's records is a necessary first step. The proposal should also be informed through a brief interview with the child's parents and education staff. These data should provide the basis for underlying referral questions and possible differential diagnosis. The proposal should also include assessment procedures to be used (be thorough and note that the proposal may be modified). The proposal should include time for in-school observations, educator interviews, timelines for report completion, and estimated cost.

\section{Record Review}

A critical component to conducting an IEE is a comprehensive review of the child's education records (see Table 3 ). Education records include all the records that are produced
Table 3 Educational records

Special education evaluations

Progress monitoring evaluations

Testing protocols

IEPs, IEP progress reports, and behavioral intervention plans

Grading reports

Attendance records

Disciplinary referrals

Documentation of the use of conditional procedures

Work samples

Correspondence between parties (teachers, parents, administrators)

by the school district and the student. While medical records may not be part of the child's school record, they are often essential to understanding the functional status of the child and should be obtained, reviewed, and considered in relation to the child's functioning in the educational setting. For example, a medical or behavioral health condition or treatment with psychoactive medication can have a significant impact on a child's performance during the IEE and in the context of their educational program.

There are number of critical findings to look for in reviewing a child's educational record. These can include but are not limited to the same IEP recycled year after year; no, inappropriate, or incomplete evaluations; failure to appropriately identify a child's disability; failure to appropriately document the child's progress; the excessive use of conditional procedures (e.g., restraint and seclusion); errors in test administration and scoring; clear acts of bad faith (e.g., lying); over-reaching parents; and a significant number of emails, sometimes signifying a breakdown in the communication process between parents and educators.

\section{School Observations}

Observations of the child in their school setting are an important component of an IEE. In conducting an IEE, the evaluation process should mirror the eligibility evaluation process as dictated by state rules, especially as it relates to observations at school. Observational opportunities may be dictated by the age, setting (mainstream versus self-contained), and grade of the child. For example, observations of a child in elementary school are likely different than a child in middle or high school, due to the likelihood that the child has a different teacher per subject area in a typical middle and high school. Ideally, observations of the child's functioning within educational settings should occur prior to meeting the examiner. There are a number of observational schemes that can be utilized for this purpose, depending on the referral question (Volpe et al 2005). It is important to consider which areas are functioning or skill areas to target for observation, as this 
would guide the examiner toward the appropriate setting for those observations. For example, observations may be directed at academic skills, attention, and executive functioning in the classroom setting. Social skills may be better observed at recess or in the cafeteria. Observations may occur in situations where the child has difficulty transitioning in structured or unstructured activities.

There are times when other professionals, such as a behavior analyst connected with an IEE, will conduct observations as the main part of their evaluation. If there is an agreement among the parties, and the examiner has experience and confidence in the other examiner's observations, the neuropsychological portion of the IEE may rely on others' observations and not necessarily conduct another observation.

\section{Educator Interviews and Behavior Rating Scales}

Obtaining the perspective of educators regarding the child's functioning at school is essential in the IEE process. Educator completion of behavior rating scales is an efficient means of obtaining an educator's perspective about a child's functioning at school and can also be used as a means of comparison of a child's behavior across the home and school environments. Having educator's responses to behavior rating scales can facilitate and streamline the interview process.

Depending on the areas of concern, age and grade of the child, and the number of staff serving a child, interviewing educators can be cumbersome and time consuming. There are instances when the interviews of educators can take part in a group format, while at other times individual educator interviews may be more appropriate. In particularly contentious cases, the school administration may request a copy of questions to be asked during educator interviews or even allow educators to respond to interview questions in writing. This method should be resisted, since providing written responses to questions does not allow for sufficient follow-up questions in response to the initial questions. Often, the follow-up questions are more important than the initial questions. In order to be thorough and obtain the educators' perspective, in-person interviews are preferable. When in-person interviews are incompatible due to geographic distance and scheduling constraints, phone or Skype interviews may be sufficient. Table 4 provides a list of questions in a case of a child with significant behavioral and emotional dysregulation.

\section{Clinic Activities}

As noted above, given the review necessary to complete an evaluation proposal, contact will have been made and releases/authorization executed prior to meeting the child and their parents. Ideally, the release of information should provide unfettered access to a child's records, educators, and
Table 4 Educator interview questions

Can you give us a timeline of Jane's difficulties?

When did you first notice things weren't going well? How did this progress?

Any other changes for Jane around the time difficulties started?

What are Jane's strengths/weaknesses?

When is she at her best?

When does she have the most difficulties?

Can you tell when she is going to have a bad day? How?

Can you tell when specific difficulties (yelling, aggression, elopement) are going to happen? How?

What happens in the classroom when Jane has difficulties? What do her peers do?

How are incidents documented? How are they communicated to her family/teachers?

Is Jane able to communicate with others regarding her difficulties?

How does she cope when upset? Are others able to help her cope?

How is the relationship between the school and Jane's family?

How is Jane's relationship with teachers?

Describe Jane's interactions with her peers. - interactions within general classroom, resource room, specials, recess, lunch.

Does she have close friends? What do they do together?

Has she been subject to bullying/harassment? Describe.

How would you describe her mood generally?

How does she do academically? On State testing?

What have you found to be helpful for Jane?

What have you tried, but found to be unhelpful?

What are current supports in place that are working?

Which school personnel have had the most success working with Jane?

What prompted the change in paraprofessional support?

Do you feel like her current educational placement is most appropriate (classroom/teacher)?

What do you feel would be most helpful for Jane now?

outside medical and behavioral health specialists (e.g., psychotherapist, counselor, and psychiatrist).

In the clinic, prior to the initiation of testing, it is important to meet with the parents and the child (depending on the child's age) to discuss how the IEE is different from the standard neuropsychological evaluation. Open discussion is advised about timelines, areas to be assessed, and the simultaneous release of the report to parents and the educational team. Most of the activities that occur in a standard outpatient neuropsychological evaluation are consistent with an IEE and will be guided by the evaluation proposal.

\section{IEE Reports}

As noted above, IEE reports are usually released simultaneously to the parties. It is good practice to mark the report as preliminary. This allows for modification based on educator and parent responses to the report. The report should be 
written in a manner that is easily understandable to both parents and educational professionals. As much as possible, jargon should be eliminated (APA Ethical Code 2010; Forensic Guidelines 1991). The report should reflect a thorough documentation of all activities conducted by the evaluator. As with a standard neuropsychological evaluation report, there should be a thorough documentation of the child's developmental and medical history, and the implication of that history on not only the child's neuropsychological profile, but most importantly, functioning in the school setting.

Unlike a standard neuropsychological report, the IEE report should include a detailed documentation of the child's educational history, which includes their progress in the general curriculum and, if appropriate, their special education program. Based on the record review and interviews of educators, parents, or the child, any concerning data reflecting a breach of procedure, protocol, and special educational rules should be documented. For example, if a child's IEP progress report documents a failure to progress on a specific IEP goal, such a fact should be documented. While the general focus of the IEE is on special education eligibility and potential programming, documenting the child's neuropsychological strengths and weakness and overall diagnostic impressions are important issues that should guide the education team as they consider the child's educational needs.

Perhaps, the most important aspect of the IEE is the analysis of special education eligibility. In order to meet this goal, the report should provide an integration of the evaluation findings with specific eligibility criteria as set out in the state's special education rules. Table 5 provides an example of the special education analysis in the case of a 14-year-old female.

The IEE should recommend appropriate evidence-based services to be delivered within the educational setting. Such recommendations may include specifics regarding the frequency and intensity of specialized instruction and the method of instruction. It may include recommendations for specific training for special education staff. Areas of evaluation and programming that have been overlooked should be documented.

Recommendations derived from clinical pediatric neuropsychological evaluation reports have been criticized for making recommendations to school programs that may be too prescriptive or even unrealistic. This practice can result in pitting parents against the school district. In the IEE process, it is very important that recommendations can be reasonably implemented and are justified based on the evaluation findings.

Treatment needs that may be delivered either outside the school or in close coordination with school staff can also be part of the recommendations from an IEE. For example, if a child has the diagnosis of generalized anxiety, recommending outpatient psychotherapy or a medication consultation is appropriate. If the anxiety impedes the child's capacity to attend
Table 5 Analysis of eligibility under the Minnesota Other Health Disabled Category (Minnesota Administrative Rules Chapter 3525, Children with a Disability, 2015)

There was ample data that Jane meets diagnostic criteria for Attention Deficit Hyperactivity Disorder Predominantly Inattentive type. This is confirmed through findings in the current evaluation and documented by Jane's physician.

Jane's diagnosis of Attention Deficit Hyperactivity Disorder along with her other chronic mental health diagnoses adversely affects her ability to complete educational tasks within routine timelines. Excessive absenteeism has been documented in the education record and she has been previously hospitalized. Jane has demonstrated diminished alertness resulting in impaired abilities, including prioritizing environmental stimuli, maintaining focus, and sustaining effort and accuracy. She clearly demonstrates based on the educational record impaired ability to manage and organize materials and complete classroom assignments within routine timelines, and impaired ability to follow directions or initiate and complete tasks.

The districts' own evaluation (January 11) stated under the heading of Physical Strength “... One teacher shared that Jane needs assistance with her school attendance. One teacher shared that Jane needs assistance with her ability to maintain school activities and produce legible and complete written work." In the school evaluation report under the heading of Alertness, it is written "... One teacher shared that Jane needs assistance with listening without distractions and demonstrates behaviors that are distracting to others. The other teacher also had concerns in this area. One teacher was concerned with her ability to accurately complete tasks and participate actively in group discussions and activities." Under the heading of Organizational Skills, it was written ".. one of her teachers shared that Jane needs assistance with organizing written work in a sequential manner, using and following her assignment notebook, and organizing and using course materials. Her other teachers shared that she is capable of being organized when she wants to be." Under the heading of Work Completion within Routine Timelines, it was written, “... Two of Jane's teachers shared she needs assistance with her ability to use her independent time appropriately, beginning and completing an assignment within the allotted time period, and has a history of late assignments. At the end of the term one teacher shared that she was missing 13 assignments and another shared she is missing more than half. One of her teachers said she needs assistance with completing tests, and another teacher shared they had concerns in this area as well. One teacher noted concerns with her (report said 'his') ability to self advocate when needed. One teacher added that she is able to follow directions and participate, but only does when she wants to." The schools' own evaluation report documented Jane's educational needs and documents the basis for consideration of special education eligibility under the OHD criteria.

school, recommending that district retain the services of a licensed psychologist to provide cognitive behavior therapy and exposure therapy to treat the anxiety and increase attendance would be appropriate.

\section{Communicating IEE Findings at a Team Meeting}

In addition to the written report, school districts often require the independent examiner to present their IEE findings during a formal team meeting. It is important that the written report is distributed, so the parties have sufficient time to review and 
formulate questions for the examiner. There are often time constraints for these meetings, especially when there are multiple independent examiners present. Communicating to the team is similar to providing feedback to parents for a clinical evaluation. The communication should begin with a general overview of parent and school district concerns and documented areas of disagreement. The child's neuropsychological functioning should be reviewed with an emphasis on implications for their functioning in the educational setting. Consistent with the written report, integrating the results of the evaluation while applying special education eligibility criteria is critical. Any opinions relative to evaluations or programing, both and good and bad, should be communicated. Always invite questions from the team and provide clarification as necessary.

\section{Testifying at a Due Process Hearing}

In the minority of cases, the parties do not settle. As a result, the independent examiner may be required to testify at a due process hearing. Due process hearings are trials, and hearing officers serve as impartial judges. Preparation is critical. Having the attorney prepare the examiner is important. At basic level, having the attorney prepare a list of questions that you will be asked can facilitate preparation. Having the attorney anticipate what questions the other attorney may ask is also important.

It is important to anticipate that the examiner may be asked questions that assess their knowledge of the state's special education rules, knowledge of test psychometric properties, knowledge of educational and diagnostic nomenclature, and recent research findings.

\section{Conclusions}

Pediatric neuropsychologists are often well qualified based on advanced assessment training and clinical experiences assessing a large variety of neurologic, neuropsychiatric, and neurodevelopmental disorders, to provide high-quality IEEs. Neuropsychologists should be mindful that IEEs are often very complex and time consuming. They require a working knowledge of special education law and rules specific to the state in which they practice. There is always the potential that the results of the IEE can be part of a due process hearing; thus, treating IEE as a forensic evaluation is recommended.

A significant limitation pediatric neuropsychologists may face as they consider engaging in the practice of IEEs is their lack of exposure to training opportunities and instruction on how to navigate the public education environment. Some neuropsychologists either during the training experience or independent clinical practice never set foot in a school or speak to educators. However, these limitations can be overcome, by making concerted efforts to engage educators in the process of conducting clinical evaluations. Many school districts provide the opportunity for outside evaluators to conduct classroom observations as part of a clinical evaluation. Educators are often eager to speak to outside providers about a particular student.

Given the close connection between pediatric neuropsychology, school psychology, and public schools as the venue for the education and specialized treatment of our patients, a singular goal should be that the findings of our evaluations are integrated into a child's educational program to enhance their functioning.

In conducting a neuropsychologically focused IEE, the examiner should be aware that the process could be an excellent opportunity to demonstrate the benefit of neuropsychological concepts and assessment procedures to public schools. It may open up avenues of further collaboration, where an outside neuropsychological evaluation or consultation is requested by a school before a conflict arises.

\section{Compliance with Ethical Standards}

Conflict of Interest The author declares that he has no conflict of interest.

Human and Animal Rights Consent This article does not contain any studies with human participants or animals performed by the author.

\section{References}

American Psychological Association. (APA). (2010). Ethical standards of psychologists and code of conduct. Washington, DC: APA.

Board of Education v. Rowley, 458 U.S. 176 (1982).

Burlington School Committee v. Department of Education, 471 U.S. 359 (1985).

Committee on Ethical Guidelines for Forensic Psychologists. (1991). Specialty guidelines for forensic psychologists. Law and Human Behavior, 15, 655-665.

Hale, J. B., \& Fiorello, C. A. (2004). School neuropsychology: a practitioner's handbook. New York: The Guilford Press.

Hurewitz, F., \& Kerr, S. (2011). The role of the independent neuropsychologist in special education. The Clinical Neuropsychologist, 25(6), 1058-1074.

Packer, I. K., \& Borum, R. (2003). Forensic training and practice. In A. M. Goldstein (Ed.), Handbook of psychology volume 11: Forensic psychology (pp. 21-32). Hoboken: Wiley.

Schaffer ex rel. Schaffer v. Weast, 546 U.S. 49, 55 (2005).

U.S. Department of Education. (2004). Individuals with disabilities improvement act of 2004, public law, 108-466. Federal Register, 70, 35802-35803.

U.S. Department of Education. (2006). 34 CFR Parts 300. Assistance to states for the education of children with disabilities and preschool grants for children with disabilities final rule. Federal Register, 71, 46590-46845.

Volpe, R. J., DiPerna, J. C., Hintze, J. M., \& Shapiro, E. S. (2005). Observing students in classroom settings: a review of seven coding schemes. School Psychology Review, 34, 454-474. 